\title{
the appliance of pig science
}

\author{
BSAS Publication No. 31 \\ Edited by JE Thompson, BP Gill and MA Varley
}

With the UK pig industry once again at a crucial crossroads, the need and willingness for better and more effective communication and collaboration between all sectors of the pig industry is gathering strength - from those involved in planning and conducting R\&D to those who can harness and benefit from it in practice.

This volume discusses how the industry, as a whole, can close the loop and meet the needs of today's researcher, processor, producer and consumer. Views are presented on five key areas of debate: Science into practice; Who matters? The changing market; A return to competitiveness; Dealing with the inevitable; Innovation and inspiration. Also included is a chapter on the nutritional control of Salmonella (workshop) together with the posters that were presented at the meeting.

\section{Contents}

Science and knowledge transfer - what the British pig industry needs - Theories, successes and lessons - Funding and facilitation - Defra's pig science and technology transfer programme $\cdot$ The multiple retailers $•$ A direct marketeers view $-A$ British point of view • Where are the gaps? • Can genetics deliver? - Regaining a high health status: Can it be done? How can it be done? - The American dream: A quest for high health - Light at the end of the tunnel - Precision pig management - resolving conflicts by integrated solutions - The production of more fast-growing heavy pigs every year - Emerging feed legislation and related issues - Current developments in pig welfare - Environmental sustainability - legislation, policy drivers and perks • Salmonella and food safety - why it matters for the British pig industry • Biotechnology - opportunities for Europe - Autofom - a new and improved technology for the UK pig industry • Effect of Formi within a Salmonella control programme for finisher pigs • The effect of floor type on ammonia emission, welfare, health and behaviour of growing pigs - Longitudinal study of adverse behaviour of undocked pigs in two different housing systems - Non-invasive endocrine assessments in the domestic sow: towards an automated reproductive monitoring system for pig production - The effect of feeding a high fibre diet from mid-lactation until breeding on subsequent litter size of sows - The effect of docosahexaenoic acid supplementation of the maternal diet on the performance and behaviour of piglets - Effect of neutraceutical supplementation on the growth performance and antioxidant activity in liver and plasma of weaned piglets - Effect of Formi, feed structure and feed processing on the gut health of pigs • Index

\section{$\sqrt{1} \frac{\text { NOTTINGHAM }}{\text { University Press }}$}




\title{
the appliance of pig science
}

\author{
BSAS Publication No. 31 \\ Edited by JE Thompson, BP Gill and MA Varley
}

With the UK pig industry once again at a crucial crossroads, the need and willingness for better and more effective communication and collaboration between all sectors of the pig industry is gathering strength - from those involved in planning and conducting R\&D to those who can harness and benefit from it in practice.

This volume discusses how the industry, as a whole, can close the loop and meet the needs of today's researcher, processor, producer and consumer. Views are presented on five key areas of debate: Science into practice; Who matters? The changing market; A return to competitiveness; Dealing with the inevitable; Innovation and inspiration. Also included is a chapter on the nutritional control of Salmonella (workshop) together with the posters that were presented at the meeting.

\section{Contents}

Science and knowledge transfer - what the British pig industry needs - Theories, successes and lessons - Funding and facilitation - Defra's pig science and technology transfer programme - The multiple retailers - A direct marketeers view $•$ A British point of view - Where are the gaps? - Can genetics deliver? - Regaining a high health status: Can it be done? How can it be done? - The American dream: A quest for high health - Light at the end of the tunnel - Precision pig management - resolving conflicts by integrated solutions - The production of more fast-growing heavy pigs every year - Emerging feed legislation and related issues - Current developments in pig welfare - Environmental sustainability - legislation, policy drivers and perks Salmonella and food safety - why it matters for the British pig industry • Biotechnology - opportunities for Europe - Autofom - a new and improved technology for the UK pig industry • Effect of Formi within a Salmonella control programme for finisher pigs • The effect of floor type on ammonia emission, welfare, health and behaviour of growing pigs - Longitudinal study of adverse behaviour of undocked pigs in two different housing systems - Non-invasive endocrine assessments in the domestic sow: towards an automated reproductive monitoring system for pig production - The effect of feeding a high fibre diet from mid-lactation until breeding on subsequent litter size of sows - The effect of docosahexaenoic acid supplementation of the maternal diet on the performance and behaviour of piglets - Effect of neutraceutical supplementation on the growth performance and antioxidant activity in liver and plasma of weaned piglets - Effect of Formi, feed structure and feed processing on the gut health of pigs • Index

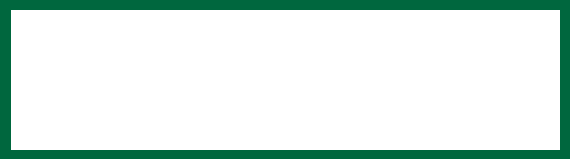




\section{British Society of Animal Science}

(formerly British Society of Animal Production)

The British Society of Animal Science aims to provide the opportunity for those with an interest in animals and animal production to exchange views, ideas and information. It is an energetic and active society with about 900 members from over 30 countries throughout the world. Today, as ever, the Society is the natural meeting point for all those with an interest in animal science. Its membership is drawn from research, education, advisory work, commerce and the practical livestock industry.

The Society organises a major scientific meeting every spring and occasional specialist meetings on key topical issues. If you would like to join or receive further information about the Society contact: The Chief Executive, BSAS, PO Box 3, Penicuik, Midlothian EH26 ORZ, UK, Tel: +44 (0)131 445 4508, Fax: +44 (0)131 5353120 , Email: BSAS@ed.sac.ac.uk, Web: www.bsas.org.uk

\section{Animal Science}

Animal Science, published six times a year both on-line and in print, is a major scientific journal of international repute, publishing fundamental and applied research including all aspects of the sciences relevant to an understanding of animals, their function and performance and their relationship to the social and physical environment. Research at the molecular, cellular, organ and system levels are all included along with research involving whole animals, production systems and mathematical modelling. Papers, both invited and submitted include areas covering breeding and genetics, nutrition and digestion, physiology and endocrinology, reproduction, lactation, health, behaviour, ethology and welfare, environment and housing, food evaluation and animal products.

Information regarding subscriptions and sales can be obtained from: BSAS Publications Dept, PO Box 3, Penicuik, Midlothian EH26 ORZ, UK, Tel: +44 (0)131 445 4508, Fax: +44 (0)131 535 3120, Email: BSAS@ed.sac.ac.uk, Web: www.bsas.org.uk 